\title{
Efeito Cardioprotetor da Suplementação Materna com Resveratrol sobre a Toxicidade Induzida por Doxorrubicina em Cardiomiócitos de Neonatos
}

\author{
Cardioprotective Effect of Maternal Supplementation with Resveratrol on Toxicity Induced by Doxorubicin in \\ Offspring Cardiomyocytes
}

\author{
Verônica Bidinotto Brito, ${ }^{1,2}$ [Deopoldo Vinicius Martins Nascimento, ${ }^{1}$ Dinara Jaqueline Moura, ${ }^{1}$ Jenifer Saffi ${ }^{1}$ \\ Universidade Federal de Ciências da Saúde de Porto Alegre, ${ }^{1}$ Porto Alegre, RS - Brasil \\ Faculdades Integradas de Taquara, ${ }^{2}$ Taquara, RS - Brasil
}

\section{Resumo}

Fundamento: A doxorrubicina (DOX) é frequentemente usada para tratar muitos tipos de cânceres, apesar da cardiotoxicidade dose-dependente. Como alternativa, o resveratrol é um polifenol que tem demonstrado efeitos cardioprotetores em vários modelos de disfunção cardíaca.

Objetivo: Este estudo investigou se o tratamento com resveratrol em ratas gestantes protege contra toxicidade induzida por doxorrubicina em cardiomiócitos da ninhada.

Métodos: Ratas Wistar (n-8) receberam sresveratrol como suplemento alimentar durante a gestação. No nascimento da ninhada, os corações (9-11) foram usados para se obter a cultura primária de cardiomiócitos. A cardiotoxicidade induzida por DOX e os efeitos da suplementação com resveratrol foram avaliados por marcadores de stress oxidativo, tais como oxidação da diclorofluoresceína diacetato, diminuição da atividade de enzimas antioxidantes, e oxidação do teor total de grupos sulfidrila, além da avaliação da viabilidade celular, geração de danos ao DNA, bem como a resposta de reparo aos danos ao DNA. Um valor de $p<0,05$ foi considerado estatisticamente significativo.

Resultados: Os cardiomiócitos de neonatos de ratas que receberam suplemento resveratrol apresentaram um aumento ( $p<0,01)$ na viabilidade das células, e diminuição $(p<0,0001)$ de células apoptóticas/necróticas após o tratamento com DOX, o que está correlacionado às atividades de enzimas antioxidantes e produção de diclorofluoresceína. Além disso, o resveratrol protegeu os cardiomiócitos de danos ao DNA induzidos por DOX, apresentando uma diminuição $(p<0,05)$ nas quebras de DNA induzidas por stress oxidativo, avaliadas pela atividade de enzimas reparadoras do DNA endonuclease III e formamidopirimidina glicosilase. A suplementação com resveratrol aumentou $(p<0,05)$ a expressão da proteína reparadora Sirt6 nos cardiomiócitos dos filhotes.

Conclusão: Essa pesquisa indica que a suplementação com resveratrol durante o período gestacional tem um efeito cardioprotetor no coração da ninhada contra a toxicidade induzida por DOX, o que pode se dever a sua função antioxidante, e o aumento na resposta de danos ao DNA.

Palavras-chave: Ratos; Resveratrol; Doxorrubicina; Cardiomiócitos; Enzimas de Reparo do DNA.

\begin{abstract}
Background: Doxorubicin (DOX) is frequently used to treat many types of cancers, despite its dose-dependent cardiotoxicity. Alternatively, resveratrol is a polyphenol that has shown useful cardioprotective effects in many heart dysfunction models.

Objective: This study investigated whether resveratrol treatment in pregnant rats protects against doxorubicin-induced toxicity in offspring cardiomyocytes.

Methods: Wistar rats $(n=8)$ were supplemented with dietary resveratrol during pregnancy. Upon the offspring's birth, hearts (9-11) were used to obtain the primary culture of cardiomyocytes. DOX-induced cardiotoxicity and the effects of resveratrol supplementation were evaluated by oxidative stress markers, such as dichlorofluorescein diacetate oxidation, decrease in the activity of antioxidant enzymes, and oxidation of total sulfhydryl content, in addition to cell viability evaluation, DNA damage generation, and DNA damage repair response. A value of $p<0.05$ was considered statistically significant.
\end{abstract}

Correspondência: Verônica Bidinotto Brito •

Universidade Federal de Ciências da Saúde de Porto Alegre - Rua Sarmento Leite, 245. CEP 90050-170, Porto Alegre, RS - Brasil

E-mail: veronicab@ufcspa.edu.br

Artigo recebido em 23/07/2020, revisado em 01/12/2020, aceito em 27/01/2021

DOI: https://doi.org/10.36660/abc.20200752 
Results: Neonatal cardiomyocytes from resveratrol supplemented rats exhibiting an increase $(p<0.01)$ in cell viability and lower $(p<0.0001)$ apoptotic/necrotic cells after DOX treatment, which correlates with the activities of antioxidant enzymes and dichlorofluorescein production. Moreover, resveratrol protected cardiomyocytes from DOX-induced DNA damage, showing a decrease $(p<0.05)$ in DNA breaks induced by oxidative stress, evaluated by the activity of DNA-repair enzymes endonuclease III and formamidopyrimidine glycosylase. Supplementation with resveratrol increased $(p<0.05)$ the expression of the repair protein Sirt6 in the cardiomyocytes of the pups.

Conclusion: This research indicates that supplementation with resveratrol during the gestational period has a notable cardioprotective effect on the offspring's heart against DOX-induced toxicity, which may well be due to its antioxidant function, and the increase in the DNA damage repair response.

Keywords: Rats; Resveratrol; Doxorubicin; Cardiomyocytes; DNA Repair Enzymes.

Full texts in English - http://www.arquivosonline.com.br

\section{Introdução}

A antraciclina doxorrubicina (DOX) é um agente quimioterápico usado geralmente usado para tratar leucemia e uma variedade de tumores sólidos. ${ }^{1}$ Sua ação citotóxica em células tumorais está relacionada à inibição da topoisomerase II; intercalação e dano ao DNA, que produzem quebras de dupla hélice; e um aumento na geração de radicais livres, que comprometem os processos de replicação e transcrição. ${ }^{2}$ Recentemente, demonstrouse que a DOX expulsa histonas de regiões específicas do genoma, causando danos à cromatina com alterações epigenéticas e transcricionais consequentes. ${ }^{3}$

O tratamento com DOX pode causar efeitos colaterais graves, demonstrando uma ação terapêutica limitada devido a sua forte cardiotoxicidade que pode levar a cardiomiopatia dependente da dose. ${ }^{4}$ No nível intracelular, muitas vias podem estar envolvidas na toxicidade induzida por DOX. Em muitos delas as espécies reativas do oxigênio (ERO) geradas pelo metabolismo da DOX têm um papel importante na disfunção miocárdica devido ao stress oxidativo. ${ }^{5}$

Não está claro se os efeitos adversos do tratamento com DOX são necessários para sua eficácia antitumoral. Algumas estratégias de redução da toxicidade foram investigadas, mas, atualmente, o agente quelante de ferro dexrazoxane é clinicamente o único método alternativo para evitar a cardiotoxicidade induzida por DOX. ${ }^{6}$

Portanto, o desafio atual é elaborar um protocolo cardioprotetor para tratamentos curtos e longos com DOX, sem impedir sua atividade antitumoral. Muitas estratégias terapêuticas, tais como a suplementação com antioxidantes ou o aumento da capacidade antioxidante pelo exercício, já foram propostas para limitar a toxicidade da DOX.,8 Surpreendentemente, dados recentemente publicados por nosso grupo de pesquisa demonstram que o exercício materno durante a gestação pode reduzir os efeitos cardiotóxicos induzidos por DOX em cardiomiócitos de filhotes de ratos. ${ }^{9}$

Nesse sentido, o resveratrol é um composto polifenólico que tem recebido atenção por seu potencial de proteção contra doenças cardiovasculares. ${ }^{10}$ Seus benefícios cardiovasculares estão relacionados aos efeitos em sistemas biológicos - evitando a agregação plaquetária, ${ }^{11}$ diminuindo a expressão da sintase do óxido nítrico, ${ }^{12}$ exercendo efeitos antioxidante e neutralizando radicais livres. ${ }^{13} \mathrm{~A}$ demanda global por terapias mais razoáveis identificou características importantes para a saúde humana no resveratrol, associada à boa relação custo benefício: baixa toxicidade e alta disponibilidade. ${ }^{14}$ Além disso, o interesse nesse composto bioativo aumentou recentemente após a identificação de sua ação protetora contra o câncer de pele. ${ }^{15}$

Moléculas bioativas presentes na dieta materna dos ratos têm recebido destaque devido a sua participação na reprogramação do metabolismo da ninhada. ${ }^{16,17}$ Como o resveratrol atravessa a membrana placentária, a suplementação pela mãe durante a gestação já foi associada a efeitos benéficos em modelos experimentais, tais como evitar a morte do embrião no curso do diabetes gestacional, ${ }^{18}$ e controle da hipertensão na prole de animais espontaneamente hipertensos. ${ }^{19}$ Entretanto, o efeito cardioprotetor, na ninhada, do resveratrol presente na dieta materna ainda não foi investigado.

Portanto, considerando os efeitos bioativos do resveratrol em doenças cardiovasculares, neste estudo testouse a hipótese de que o resveratrol, presente na dieta materna durante o período gestacional, tem um efeito cardioprotetor na toxicidade induzida por DOX na cultura de cardiomiócitos da ninhada, por meio de seus possíveis efeitos no sistema de defesa antioxidante e na resposta ao dano de DNA.

\section{Métodos}

\section{Animais}

Ratos Wistar adultos machos e fêmeas (provenientes do Biotério da UFCSPA) pesando entre 70-100 g foram abrigados em condições controladas de luz, temperatura e umidade (períodos de $12 \mathrm{~h}$ luz/escuridão, a $22^{\circ} \mathrm{C} \pm 2$, e $55 \% \pm 5$ de umidade relativa), com água e dieta padrão ad libitum. Essa pesquisa foi realizada em conformidade com as diretrizes nacionais e internacionais sobre o uso de animais para fins científicos, e foi aprovada pelo Comitê de Ética da UFCSPA e registrado sob o número de protocolo 183/13.

\section{Protocolo experimental}

O procedimento de acasalamento foi realizado após o primeiro ciclo estral. Na manhã seguinte ao procedimento de acasalamento, esfregaços vaginais foram analisados para detectar espermatozoides, que era a confirmação do dia zero 
da gestação. Em seguida, as fêmeas foram distribuídas nos seguintes grupos:

Grupo controle $(C-G, n=8)$ : sem suplementação com resveratrol. Recebiam solução salina com 0,05\% de Tween 80 por gavagem, e eram manipuladas uma vez por dia, 5 dias/semana, durante 21 dias de gestação, totalizando 15 dias de gavagem.

Grupo resveratrol (RV-G, $\mathrm{n}=8$ ): suplementado com 2,5 $\mathrm{mg} / \mathrm{kg}$ de peso corporal com resveratrol ${ }^{20}$ (dispersado em solução salina com $0,05 \%$ de Tween 80 ) ${ }^{21}$ por gavagem (uma vez por dia, 5 dias/semana, durante 21 dias de gestação, totalizando 15 dias de suplementação).

Para a estimativa do tamanho da amostra, a pesquisa de Singh et al., ${ }^{18}$ foi utilizada como referência. Para isso, um teste bicaudal foi aplicado, com um nível de significância de $5 \%$ e poder de $95 \%$. Estimou-se uma diferença mínima entre os grupos de $12 \mathrm{nmol} / \mathrm{mg}$ de proteína, com um desvio padrão de 0,096, para resultar em uma avaliação significativa do teste de grupos sulfidrila utilizado para estimativa da amostra. A estimativa do tamanho da amostra resultou em oito animais por grupo.

Ao final do período gestacional, filhotes de até 3 dias de idade foram submetidos à eutanásia e seus corações ${ }^{9-11}$ foram usados para obter um agregado de cardiomiócitos usado para a cultura primária, como demonstrado na linha do tempo simplificada da Figura 1.

\section{Cultura de cardiomiócitos}

A cultura primária dos corações de ratos neonatos foi obtida conforme descrito previamente por nosso grupo de pesquisa. ${ }^{9}$ Em resumo, os corações foram submetidos a ciclos repetidos de uma digestão enzimática em um tampão contendo pancreatina e BSA, a $37^{\circ} \mathrm{C}$. Ao final dos ciclos, o agregado de células foi colocado em frascos de cultura de $75 \mathrm{~cm}^{2}$ para adesão de fibroblastos. A suspensão celular foi aspirada, centrifugada e disposta em placas de cultura tratadas com gelatina $(0,1 \%$ em PBS) para adesão de cardiomiócitos. Quando as células haviam adquirido confluência, a cultura foi tratada com $\operatorname{DOX}(0,1,0,5$ ou $1,0 \mu \mathrm{M})$ durante 24 ou $48 \mathrm{~h}$ para a análise descrita abaixo.
Todos os experimentos foram realizados em triplicata, para garantir a precisão dos resultados.

\section{Ensaio de viabilidade celular e mecanismos de morte}

O teste azul de tripan (TB) foi utilizado para avaliar a viabilidade das células. ${ }^{22} \mathrm{O}$ número de células viáveis e células mortas foi contado em um contador de células automático (Countess $\left.{ }^{\circledR}\right)$, que permite estimar a porcentagem de células viáveis (relação células viáveis/células totais). Desse ponto em diante, o mecanismo de morte foi avaliado pela citometria de fluxo. Depois do tratamento com DOX, a cultura de cardiomiócitos foi lavada, centrifugada e ressuspensa em tampão aglutinante $(100 \mu \mathrm{L})$ com Anexina V-PE $(3 \mu \mathrm{L})$ e $7-A A D$ $(3 \mu \mathrm{L})$, e depois incubada no escuro por 15 minutos. Foram realizadas análises por citometria de fluxo, considerando 5.000 eventos/amostra, para acessar as células viáveis, apoptóticas ou necróticas (FACSCalibur com software CellQuest).

\section{Detecção de danos no DNA}

A genotoxicidade induzida por DOX foi avaliada pelo índice de danos ao DNA, por meio do ensaio do cometa alcalino descrito previamente. ${ }^{23,24}$ Após o tratamento, a cultura de cardiomiócitos foi lavada, tripsinizada, centrifugada e ressuspensa em PBS. Trinta $\mu \mathrm{L}$ de suspensão celular foram dissolvidos em $0,75 \%$ agarose (com baixo ponto de fusão) que foi distribuída em uma lâmina previamente coberta com agarose a 1\% (com ponto de fusão normal). Lâminas de microscópio foram incubadas em solução de lise durante 24 horas a $4^{\circ} \mathrm{C}$. Para avaliar a presença de danos oxidativos ao DNA, as lâminas foram retiradas da solução de lise, lavadas e incubadas com enzimas reparadoras - endonuclease III (EndollI) ou formamidopirimidina glicosilase (FPG) - (300 mU/ gel; $45 \mathrm{~min}$ a $37^{\circ} \mathrm{C}$ ). Depois da lise e/ou incubação com Endolll ou FPG, o DNA foi desenrolado por 20 minutos em um sistema de eletroforese horizontal contendo tampão alcalino fresco (300 mM NaOH/1 mM EDTA a pH 13,0). A expressão de sítios alcali-lábeis do DNA ocorreu por migração dos danos ao DNA sob corrente elétrica (25 V; $300 \mathrm{~mA} ; 0,9 \mathrm{~V} / \mathrm{cm}$ ). As lâminas foram antes neutralizadas e coradas como descrito previamente..$^{25} \mathrm{Um}$ total de 100 células/lâminas foi visualizado por microscopia ótica, e classificado de acordo com o método descrito previamente. ${ }^{26}$

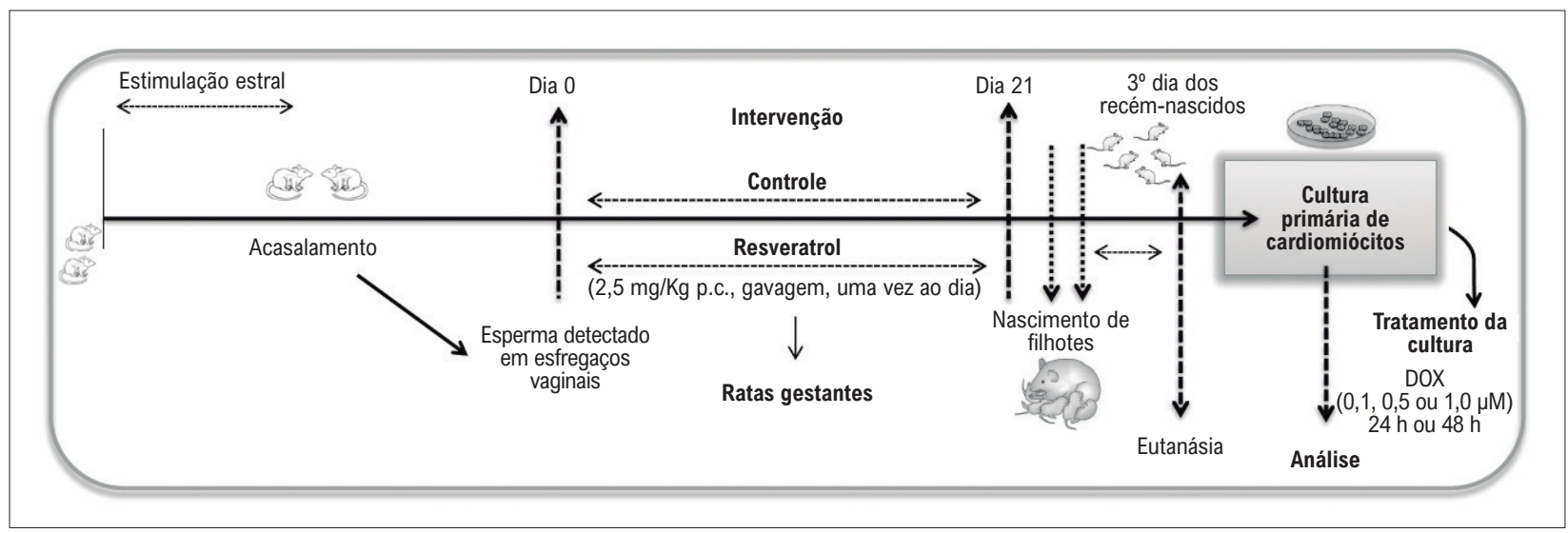

Figura 1 - Linha de tempo simplificada do protocolo experimental. 


\section{Extratos proteicos de cardiomiócitos}

Depois de 24 ou 48 horas de tratamento com DOX, o meio celular foi retirado, e os extratos proteicos de cardiomiócitos foram preparados como descrito anteriormente, ${ }^{9}$ os quais foram utilizados para todas as análises adicionais descritas abaixo.

\section{Quantificação do stress oxidativo}

A diclorofluoresceína diacetato $\left(\mathrm{H}_{2}\right.$ DCF-DA) é uma sonda que é hidrolisada por esterases de meio intracelular para formar um produto não fluorescente o qual é oxidado por oxidantes intracelulares gerando uma diclorofluoresceína fluorescente (DCF). ${ }^{27}$ Resumidamente, a $\mathrm{H}_{2}$ DCF-DA foi incubada com extrato proteico de cardiomiócito conforme descrito anteriormente, ${ }^{9}$ e a intensidade da fluorescência foi medida em um leitor de microplacas (SpectraMax M2e, Molecular Devices, California) a 480 пm (EX) e 535 пm (EM).

\section{Sistema de defesa antioxidante}

A atividade do sistema de defesa antioxidante de cardiomiócitos neonatais foi avaliada por meio da atividade enzimática de catalase (CAT) e superóxido dismutase (SOD), conforme descrito anteriormente. ${ }^{28,29} \mathrm{O}$ teor de sulfidrila total, que é inversamente proporcional aos danos oxidativos em proteínas, foi estimado pelo método descrito previamente. ${ }^{30}$

\section{Resposta aos danos ao DNA}

A resposta dos cardiomiócitos aos danos ao DNA induzidos por DOX foi avaliada pelo ensaio de immunoblotting da Sirt6 (sirtuína 6), uma desacetilase de histonas que age como uma proteína scaffold no reparo dos danos ao DNA. Para esse ensaio, $25 \mu \mathrm{g}$ de proteína de cardiomiócitos foram separadas por um SDS-PAGE a $12 \%$ por um método anteriormente descrito. ${ }^{31}$ Membranas foram incubadas com anti-Sirt6 e actina (C-2), a 1:500. O blot foi revelado utilizando-se um kit de quimiluminescência (ECL, Thermo Scientific). As densidades óticas dos immunoblots foram determinadas com o software ImageJ 1.48v (Wayne Rasband, National Institutes of Health, EUA).

\section{Quantificação da proteína}

A concentração de proteína dos extratos proteicos foi determinada conforme descrito anteriormente. ${ }^{32}$

\section{Análise estatística}

Os dados foram analisados utilizando-se o software Statistical Package for the Social Sciences (SPSS) versão 16.0 (IBM Company, Armonk, NY, EUA). A distribuição normal e a homogeneidade das variâncias foram avaliadas pelos testes de Kolmogorov-Smirnov e Levene, respectivamente. A análise de variância de uma via (ANOVA) e o teste de Tukey post hoc foram usados para a comparação entre os grupos. As correlações foram realizadas pelo coeficiente de correlação de Pearson. Os dados foram expressos como média \pm erro padrão de média (EPM) e um $p<0,05$ foi considerado significativo.

\section{Resultados}

0 resveratrol atenuou a apoptose e a necrose induzida por DOX em cardiomiócitos de neonatos

Os efeitos da suplementação materna com resveratrol durante a gestão foram avaliados inicialmente pelo teste de exclusão com azul de tripan (TB) (Figura 2), que evidenciou a morte celular dependente da concentração de DOX. Entretanto, a suplementação com resveratrol durante a

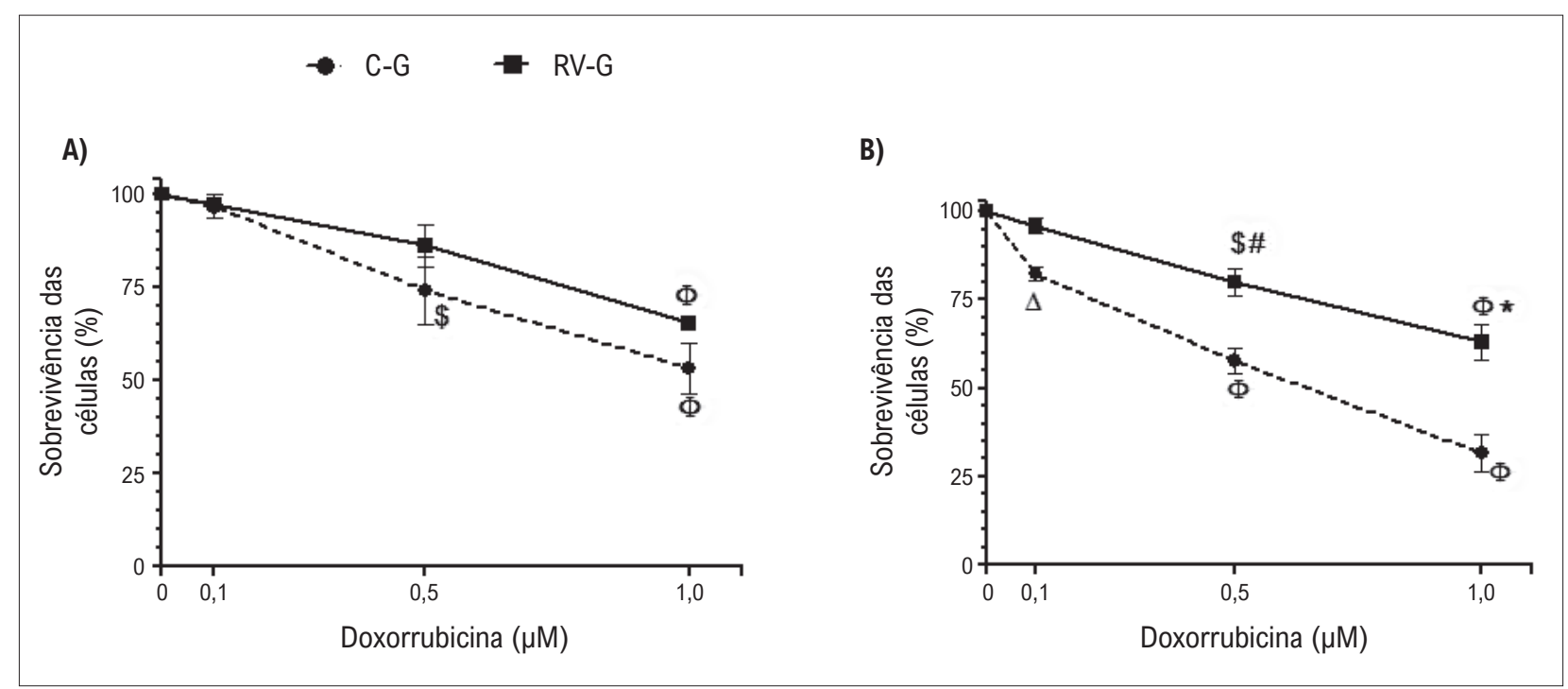

Figura 2 - Viabilidade de cardiomiócitos de neonatos expostos a DOX $(0,1,0,5$ ou $1,0 \mu M)$ por $24 h$ (A) ou $48 h(B)$, pelo teste de exclusão azul de tripano (TB). Cultura de cardiomiócitos de ninhadas de ratas suplementadas com resveratrol (2,5 mg/Kg) (RV-G) ou grupo de controle (C-G). Os valores são média $\pm \operatorname{EPM}(n=8) .0$ símbolo *indica $p<0,001, \# p<0,01$, e $p<0,05$ entre o grupo RV-G e o grupo C-G. O símbolo $\Phi$ indica $p<0,001, \$ p<0,01$, e $\Delta p<0,05$ de células de controle (não expostas ao DOX), pelos testes de ANOVA de uma via, e teste post hoc de Tukey. 
gestação protegeu células de neonatos da morte induzida após $48 \mathrm{~h}$ do tratamento com 1,0 ou 0,5 $\mu \mathrm{M}$ DOX (Figura 2B), em relação aos cardiomiócitos de neonatos de ratas não suplementadas.

Na sequência, o principal mecanismo de morte de cardiomiócitos foi explorado por citometria de fluxo (Figura 3). Os resultados confirmam os obtidos pelo ensaio TB, demonstrando um aumento na morte de cardiomiócitos relacionada ao tratamento com DOX, exibindo a fração mais alta da morte celular por apoptose na concentração de $1 \mu \mathrm{M}$ DOX ( $p<0,001)$. Esses resultados também demonstram que a apoptose é o principal mecanismo de morte induzida por DOX em cardiomiócitos de neonatos (Figura 3A), corroborando resultados prévios de nosso grupo de pesquisa. ${ }^{9}$ Além disso, o resveratrol protegeu cardiomiócitos contra a morte induzida por DOX $48 \mathrm{~h}$ após o tratamento, com um aumento de células viáveis ( $p<0,001)$ e redução de células apoptóticas e necróticas $(p<0,001)$ (Figura 3B).

\section{O stress oxidativo é atenuado em células neonatais pela suplementação com resveratrol durante a gestação}

O mecanismo mais aceito para a toxicidade induzida por DOX é a formação de ERO, que, por sua vez, leva à formação do stress oxidativo. ${ }^{5}$ As Figuras 4A e B demonstram que os cardiomiócitos de neonatos expostos à DOX apresentaram um aumento ( $p<0,001)$ na produção de oxidantes intracelulares, em relação ao grupo de controle (células não expostas à DOX). É importante observar que a suplementação com resveratrol durante a gestação atenuou $(p<0,05)$ o stress oxidativo em células neonatais após o tratamento com 0,5 ou 1,0 $\mu \mathrm{M}$ DOX (Figura 4B), em relação grupo de controle (C-G). Além disso, a viabilidade celular e a produção do stress oxidativo, também medidos pela oxidação de DCF, apresentaram-se inversamente proporcionais em 24 e $48 \mathrm{~h}(\mathrm{r}=-0,8, \mathrm{p}<0,0001$ e $r=-0,789, p<0,001)$, respectivamente. Notadamente, uma correlação direta entre a produção de stress oxidativo intracelular e a apoptose $(r=0,836, p<0,0001, r=0,817$, $\mathrm{p}<0,0001$ ) observou-se após o tratamento com o DOX, 24 $\mathrm{h}$ e $48 \mathrm{~h}$, respectivamente.

\section{0 resveratrol reduz danos oxidativos ao DNA induzidos por DOX em cardiomiócitos de neonatos}

O stress genotóxico induzido por DOX foi avaliado pelo ensaio cometa alcalino, que detecta os sítios alcali-lábeis e quebra de hélices no DNA. ${ }^{33}$ Os resultados demonstram um aumento nos danos ao DNA induzidos por DOX em células neonatais de todos os grupos de mães (Figuras $5 A-B)$, que era dependente de concentração. Entretanto, a suplementação gestacional com resveratrol protegeu cardiomiócitos de danos ao DNA induzidos por DOX.

Considerando que a produção do stress oxidativo induzido por DOX foi reduzido $(p<0,05)$ pelo resveratrol (Figura 4), a avaliação dos danos ao DNA relacionados ao stress oxidativo gerado por DOX se torna uma questão importante. Dessa forma, foi examinada a atividade das enzimas reparadoras do DNA endonuclease III (EndolII) e formamidopirimidina glicosilase (FPG) ampliando a especificidade do ensaio de cometa, reconhecendo bases danificadas por stress oxidativo e convertendo em quebras de fita simples. ${ }^{26,34}$ A Figura 5 (C-F) demonstra que a magnitude dos danos oxidativos ao DNA causado pelo tratamento com DOX que foi reconhecido pelas enzimas reparadoras. Notadamente, os cardiomiócitos neonatais

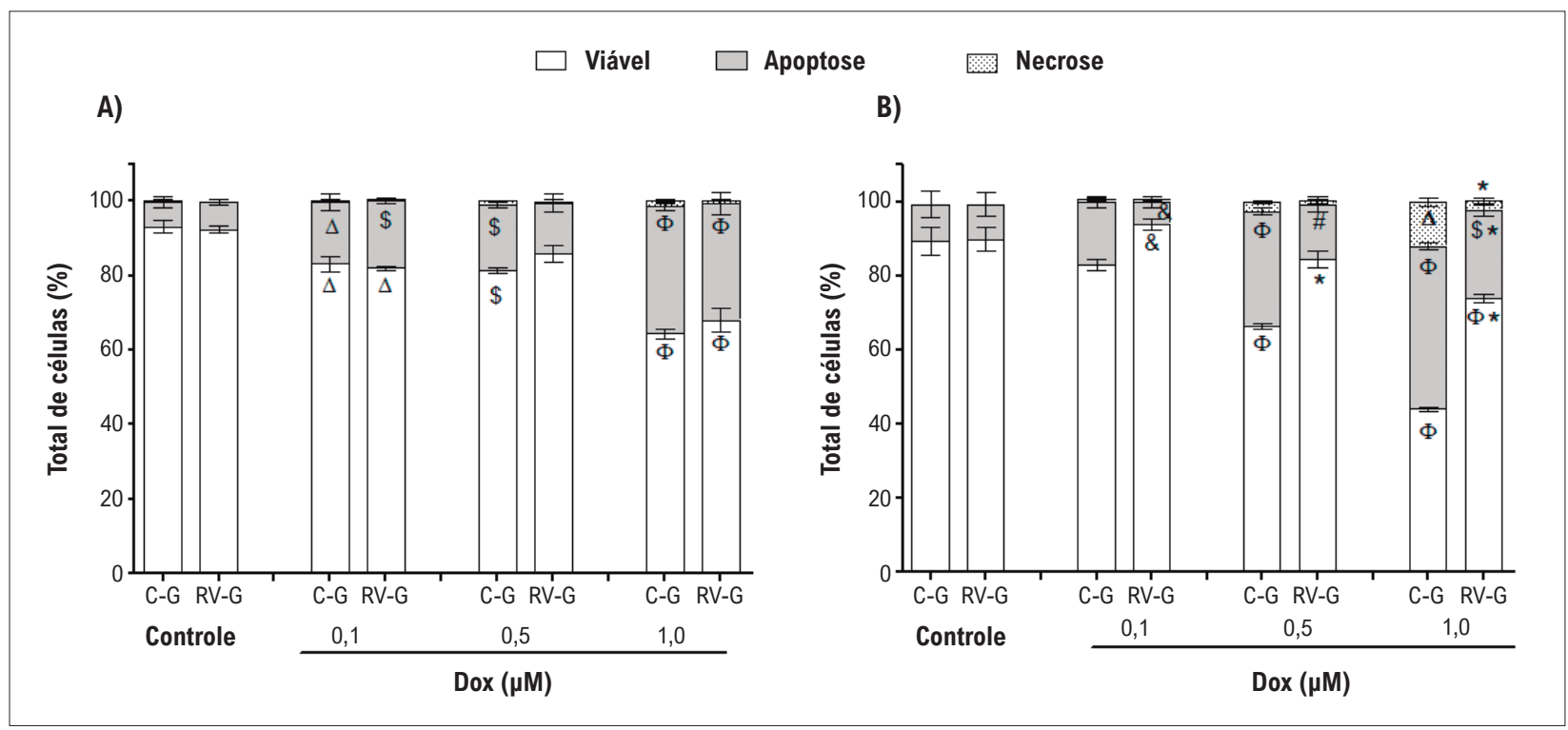

Figura 3 - Cultura de cardiomiócitos de ninhadas de ratas suplementadas com resveratrol (2,5 mg/Kg) (RV-G) ou grupo de controle (C-G) foi analisada por citometria de fluxo. Depois de $24 \mathrm{~h}(\mathrm{~A})$ ou $48 \mathrm{~h}(\mathrm{~B})$ de tratamento com DOX (0,1, 0,5 ou 1,0 $\mu \mathrm{M})$ foram analisadas a viabilidade, a apoptose, ou a necrose de cardiomiócitos de neonatos. 0 grupo de controle indica células sem DOX. Os valores são média $\pm E P M(n=8)$. 0 símbolo * indica $p<0,001$, \# $p<0,01$, e $p<0,05$ entre o grupo RV-G e o grupo C-G. 0 símbolo $\Phi$ indica $p<0,001, \$ p<0,01$, e $\Delta p<0$,05 de células de controle (não expostas ao D0X), pelos testes ANOVA de uma via, e seguido por post hoc Tukey. 


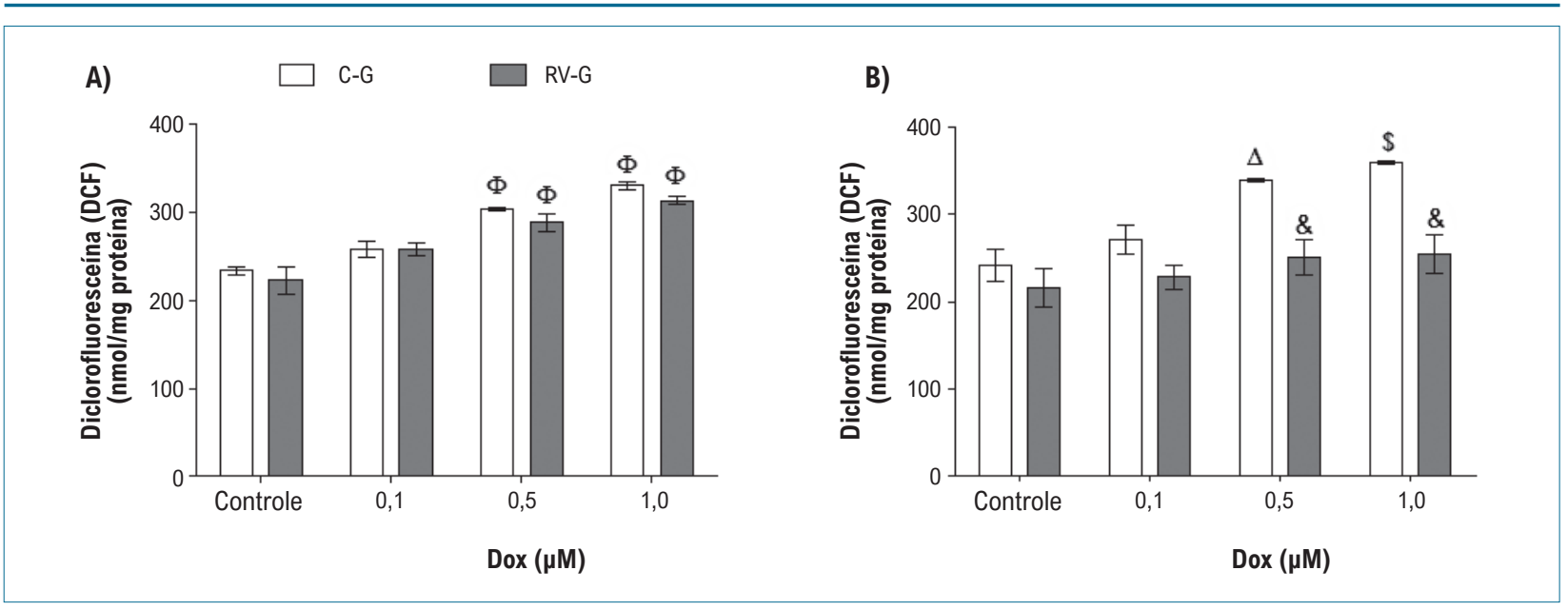

Figura 4 - Stress oxidativo em cardiomiócitos de neonatos tratados com DOX (0,1, 0,5 ou 1,0 $\mu M)$ por 24 h (A) ou 48 h (B). Os valores são média \pm EPM $(n=8)$. 0 símbolo \& indica $p<0,05$ entre o grupo RV-G e o grupo $C$-G. 0 símbolo $\Phi$ indica $p<0,001, \$ p<0,01$, e $\Delta p<0,05$ de células controle (não expostas à DOX), pelos testes ANOVA de uma via, seguido por post hoc Tukey.

de mães suplementadas apresentaram uma diminuição ( $p<0,001)$ em danos oxidativos observados no DNA. Além disso, a suplementação com resveratrol conseguiu diminuir os danos oxidativos ao DNA de cardiomiócitos neonatais não expostos a DOX, 24 e 48 h após o tratamento com DOX.

Os cardiomiócitos de neonatos de mães suplementadas com resveratrol apresentaram um sistema de defesa antioxidante mais eficiente

Com o objetivo de avaliar se os efeitos do resveratrol sobre a geração do stress oxidativo danos ao DNA estão associados com um aumento no sistema de defesa antioxidante, foram examinadas as atividades das enzimas CAT e SOD (Tabela 1), bem como o teor total de grupos sulfidrila (Figura 6). As atividades das enzimas CAT e SOD foram reduzidas por DOX em cardiomiócitos neonatais das mães do grupo controle em comparação com as células neonatais de mães que receberam o suplemento resveratrol (Tabela 1).

A análise de correlação demonstrou que a atividade da CAT apresenta uma correlação inversa com a produção do stress oxidativo $(r=-0,763, p<0,0001$ e $r=-0,808, p<0,0001) 24$ e 48 horas após ao tratamento com DOX, respectivamente. O mesmo efeito foi verificado para a SOD, com uma correlação inversa com o stress oxidativo $(r=-0,527, p<0,004$ e $r=-0,671, p<0,0001) 24$ e 48 horas após ao tratamento com DOX, respectivamente. Particularmente, o resveratrol bloqueou a redução do teor total de grupos sulfidrila em células neonatais, nos dois momentos do tratamento com DOX (Figura 6), sem efeito protetor em 1,0 $\mu \mathrm{M}$ de DOX (Figura 6B).

\section{A expressão da Sirt6 e resposta aos danos ao DNA são} aumentadas nos cardiomiócitos de mães suplementadas

A análise de immunoblotting demonstrou que a suplementação de ratas com resveratrol durante a gestação induziram um aumento ( $p<0.01$ ) na expressão da proteína Sirt6 de cardiomiócitos neonatais em relação às células neonatais do grupo de controle. É importante notar que esse aumento da expressão de Sirt6 dependeu da concentração de DOX (Figura 7).

\section{Discussão}

Neste estudo, confirmou-se a hipótese de que o resveratrol, presente na dieta materna durante o período gestacional, tem um efeito cardioprotetor na toxicidade induzida por DOX na cultura de cardiomiócitos da ninhada, por meio do aumento no sistema de defesa antioxidante e na resposta ao dano de DNA.

A cardiotoxicidade relacionada à concentração de DOX foi observada em cardiomiócitos de neonatos de mães que não receberam resveratrol, com um aumento da morte celular. Confirmando os mecanismos de toxicidade celular induzida por DOX elucidados previamente, neste estudo a apoptose também foi o principal mecanismo da morte dos cardiomiócitos. A suplementação materna com 2,5 mg/kg de resveratrol por dia, durante o período gestacional, protegeu o coração neonatal contra a cardiotoxicidade induzida por DOX, com um aumento na viabilidade celular, também diminuindo as células apoptóticas, o que correlacionou-se com a redução da produção do stress oxidativo às $24 \mathrm{e}$ 48 horas. Além disso, o resveratrol evitou a redução da atividade de SOD induzida por DOX e levou ao aumento da atividade do CAT, em células neonatais de mães que receberam o suplemento. Além das enzimas antioxidantes, os cardiomiócitos neonatais de mães que receberam resveratrol apresentaram um aumento no teor total de grupos sulfidrila, protegendo contra os efeitos oxidativos induzidos por DOX. Esses resultados são favoráveis à hipótese de que a suplementação materna com resveratrol durante a gestação pode modular respostas a agentes estressantes da prole.

A DOX é uma droga quimioterápica frequentemente utilizada na clínica, apesar de seus efeitos cardiotóxicos cumulativos dependentes da dose. ${ }^{1} \mathrm{O}$ desenvolvimento de estratégias terapêuticas adicionais para reduzir os efeitos 
A)

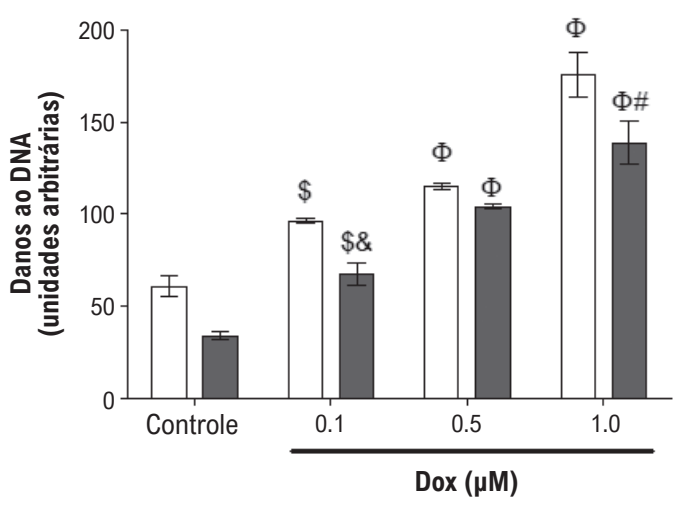

C)

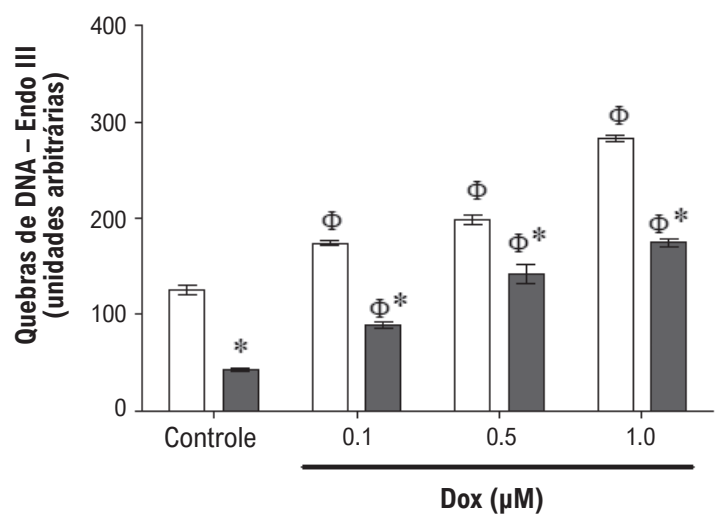

E)

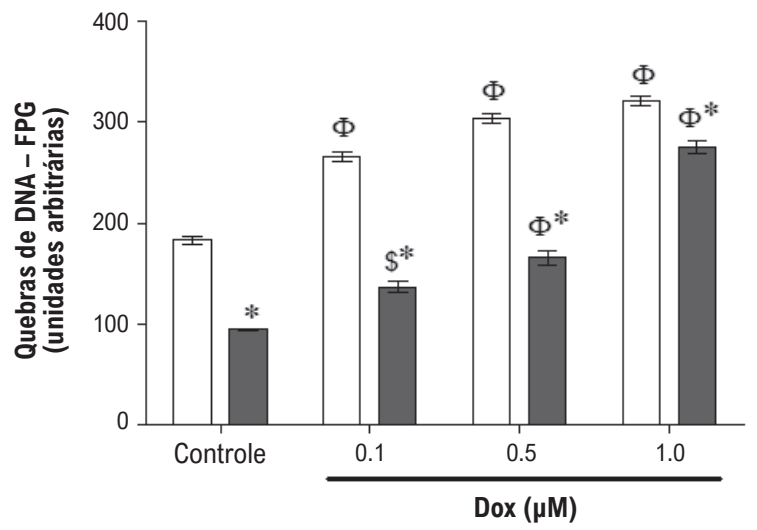

RV-G

B)

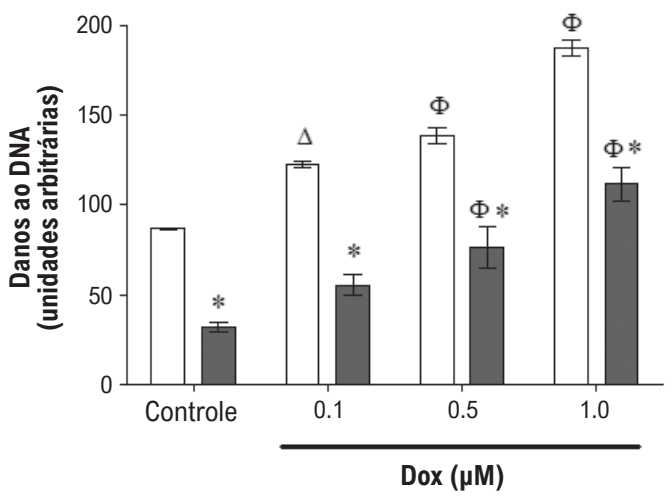

D)

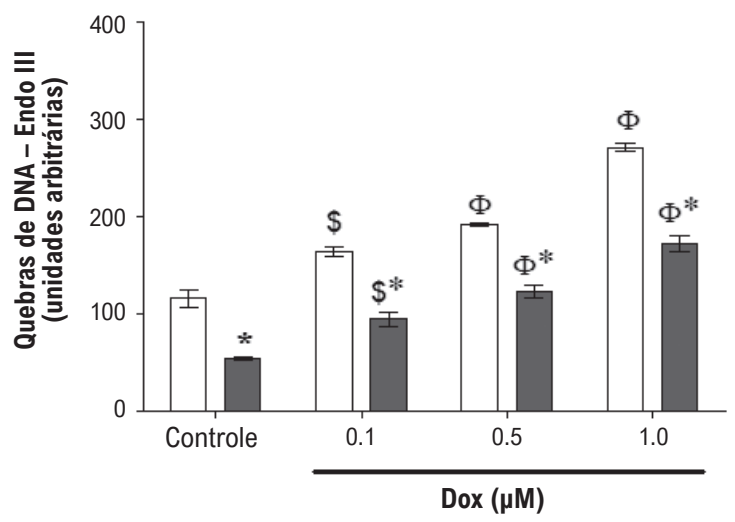

F)

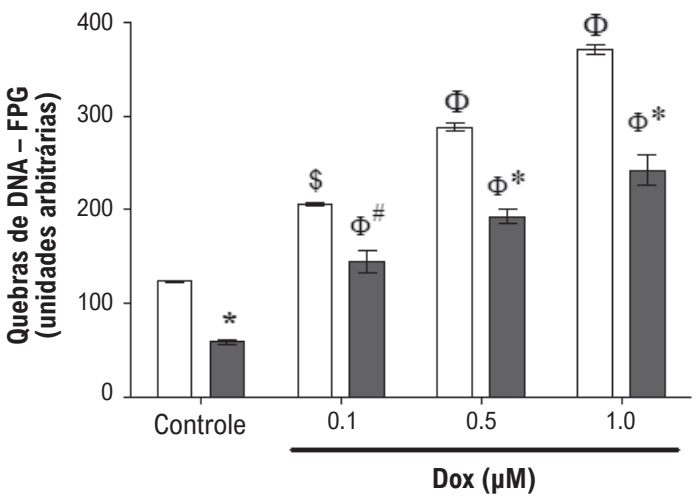

Figura 5 - Danos ao DNA em cardiomiócitos de neonatos tratados com DOX (0,1, 0,5 ou 1,0 $\mu \mathrm{M})$ por $24 \mathrm{~h}$ (A) ou $48 \mathrm{~h}$ (B). Os danos oxidativos ao DNA foram analisados pelas enzimas endonuclease III (EndolII) e formamidopirimidina glicosilase (FPG) nas células tratadas com DOX por $24 \mathrm{~h}$ (C e E) ou 48 $h(D$ e F). Os valores são média \pm EPM $(n=8)$. 0 símbolo *indica $p<0,001, \# p<0,01$, e $p<0,05$ entre o grupo $R V-G$ e o grupo $C$ - . 0 símbolo $\Phi$ indica $p<0,001, \$ p<0,01$, e $\Delta p<0,05$ de células controle (não expostas à $D O X$ ), pelos testes ANOVA de uma via, seguido do teste post hoc Tukey. 
Tabela 1 - Efeitos da suplementação gestacional com resveratrol nas atividades das enzimas SOD e CAT de cardiomiócitos de neonatos expostos à DOX.

\begin{tabular}{|c|c|c|c|c|}
\hline & Controle & Resveratrol & Controle & Resveratrol \\
\hline & \multicolumn{4}{|c|}{ SOD (U/mg proteína) } \\
\hline & \multicolumn{2}{|c|}{24 horas } & \multicolumn{2}{|c|}{48 horas } \\
\hline Controle & $4,61 \pm 0,31$ & $6,26 \pm 0,61^{*}$ & $4,46 \pm 0,15$ & $6,00 \pm 0,73$ \\
\hline $0,1 \mu \mathrm{M}$ DOX & $3,90 \pm 0,39$ & $5,31 \pm 0,19^{*}$ & $3,98 \pm 0,05^{\#}$ & $6,06 \pm 0,50^{*}$ \\
\hline $0,5 \mu \mathrm{M}$ DOX & $3,22 \pm 0,42^{\#}$ & $5,22 \pm 0,37^{*}$ & $3,03 \pm 0,37^{\#}$ & $5,12 \pm 0,42^{*}$ \\
\hline \multirow[t]{3}{*}{$1,0 \mu \mathrm{M} \mathrm{DOX}$} & $2,83 \pm 0,20^{\#}$ & $5,56 \pm 0,32^{*}$ & $2,53 \pm 0,54^{\#}$ & $5,19 \pm 0,69^{*}$ \\
\hline & \multicolumn{4}{|c|}{ CAT (U/mg proteína) } \\
\hline & \multicolumn{2}{|c|}{24 horas } & \multicolumn{2}{|c|}{48 horas } \\
\hline Controle & $12,15 \pm 1,25$ & $24,08 \pm 1,31^{*}$ & $12,30 \pm 0,54$ & $27,11 \pm 1,28^{*}$ \\
\hline $0,1 \mu \mathrm{M}$ DOX & $6,16 \pm 0,41^{\#}$ & $13,00 \pm 2,15^{\text {*\# }}$ & $7,85 \pm 0,59^{\#}$ & $13,56 \pm 1,31^{\text {*\# }}$ \\
\hline $0,5 \mu \mathrm{M}$ DOX & $4,04 \pm 0,28^{\#}$ & $9,47 \pm 1,26^{\text {*\# }}$ & $5,35 \pm 0,36^{\#}$ & $12,24 \pm 1,94^{* \#}$ \\
\hline $1,0 \mu \mathrm{M}$ DOX & $2,62 \pm 0,11^{\#}$ & $8,78 \pm 1,86^{\text {*\# }}$ & $2,68 \pm 0,75^{\#}$ & $8,36 \pm 0,80^{\star \#}$ \\
\hline
\end{tabular}

As células foram tratadas com DOX $(0,1,0,5$ ou $1,0 \mu M)$ durante 24 ou $48 \mathrm{~h}$. Os valores são média $\pm E P M(n=8)$. * indica $p<0,05$ entre resveratrol e grupo de controle, e \# indica $p<0,05$ do grupo controle (células sem DOX), pelo teste ANOVA de uma via e seguido do teste post hoc Tukey.

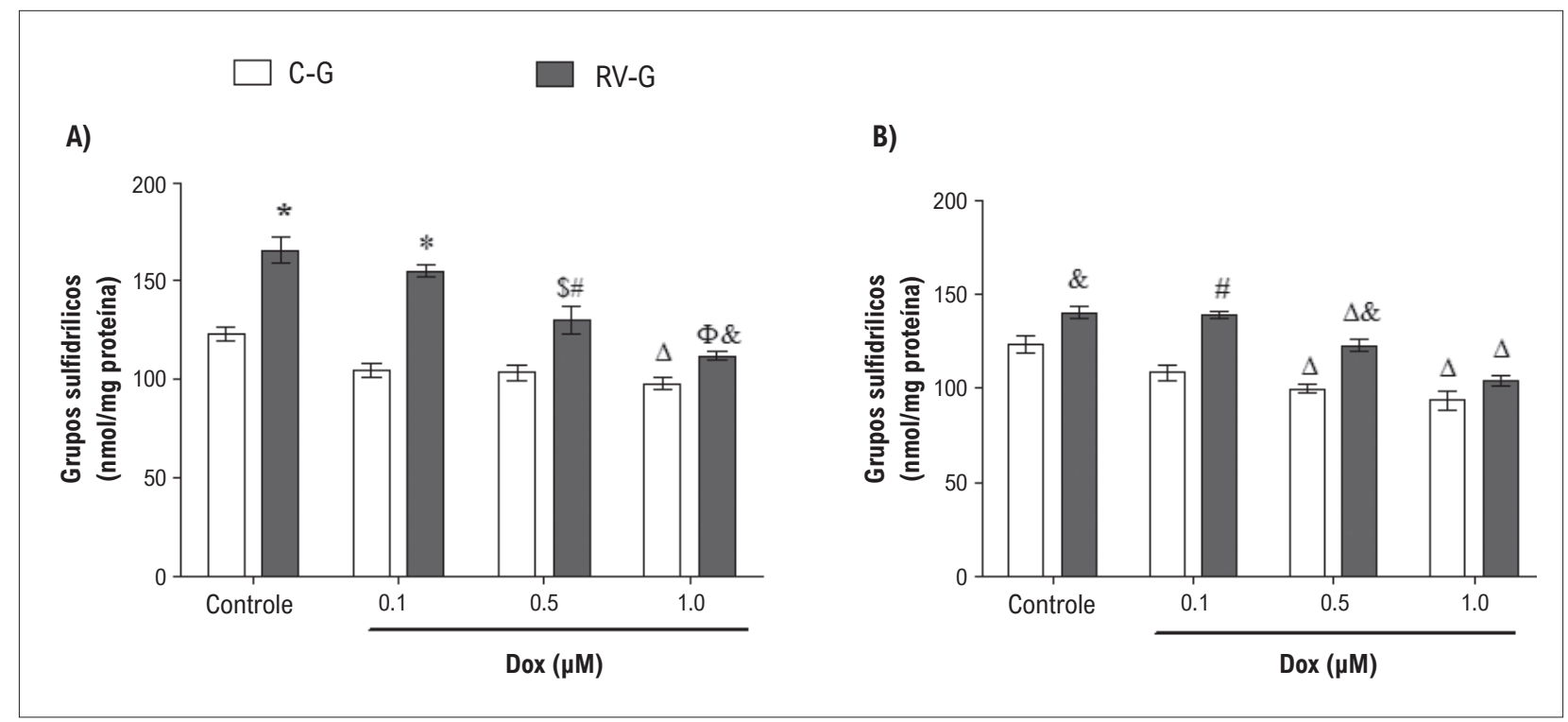

Figura 6 - Total de grupos sulfidrilicos de cardiomiócitos neonatais tratados com DOX $(0,1,0,5$ ou 1,0 $\mu \mathrm{M})$ por $24 \mathrm{~h}(\mathrm{~A})$ ou $48 \mathrm{~h}$ (B). Os valores são média $\pm \operatorname{EPM}(n=8) .0$ simbolo * indica $p<0,001$, \# $p<0,01$, e $p<0,05$ entre o grupo RV-G e o grupo C-G. 0 símbolo $\Phi$ indica $p<0,001, \$ p<0,01, e \Delta p<0,05$ de células controle (não expostas à DOX), pelos testes de ANOVA de uma via, seguido do teste post hoc Tukey.

colaterais do tratamento é essencial, tendo em vista o aumento da expectativa de vida por décadas após a terapia anticâncer. Pesquisas experimentais e clínicas, bem como a medicina preventiva destacam os benefícios do resveratrol em doenças cardiovasculares e metabólicas, ${ }^{10}$ e, mais recentemente, nas ninhadas de animais que receberam o resveratrol durante a gestação. ${ }^{18,19}$

Estruturalmente, o resveratrol pode ser apresentado em isoformas cis ou trans, com uma atividade biológica relacionada principalmente ao isômero trans. ${ }^{35}$ Devido aos anéis aromáticos presentes em sua estrutura, o resveratrol age como antioxidante, neutralizando radicais de hidroxila e a geração de stress oxidativo. ${ }^{36}$ Além disso, outros efeitos protetores no sistema cardiovascular podem estar relacionados a sua ação de neutralização do $\mathrm{H}_{2} \mathrm{O}_{2}$, retardando o stress oxidativo e evitando a morte celular endotelial induzida por ERO. ${ }^{37}$ Como o resveratrol consegue cruzar a membrana placentária, afetando o feto diretamente, ${ }^{18}$ é possível que os efeitos cardioprotetores observados no estudo sejam uma ação direta do resveratrol na neutralização de ERO induzido por DOX. Além disso, a redução na produção do stress oxidativo também 


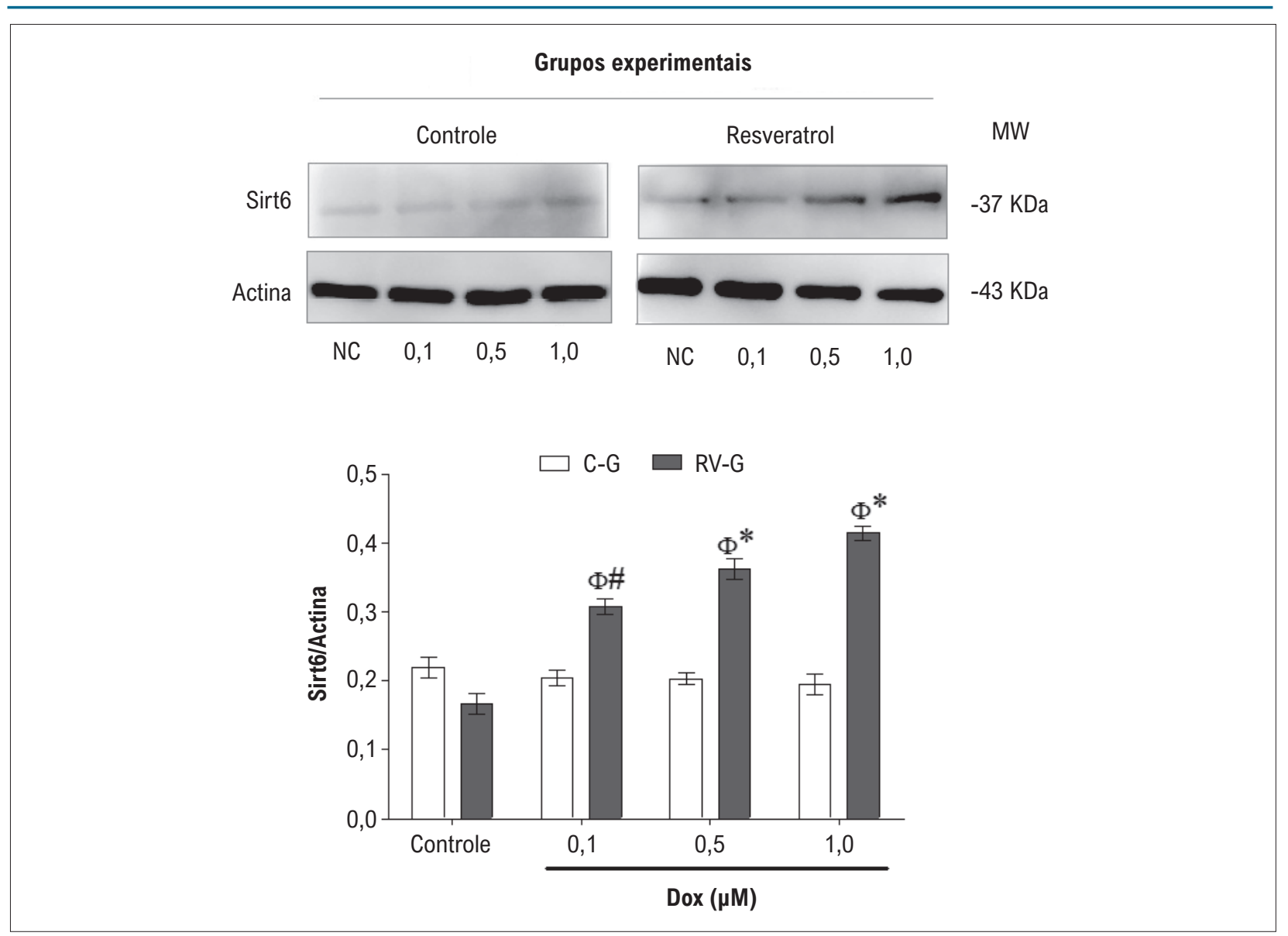

Figura 7 - Expressão proteica de Sirt6 de cardiomiócitos neonatais tratados com DOX (0,1, 0,5 ou 1,0 $\mu \mathrm{M})$ por $48 \mathrm{~h}(\mathrm{~A})$ ou $48 \mathrm{~h}$ (B). 0 gráfico de barras corresponde à média \pm EPM dos valores de quantificação da relação Sirt1/actina de todas as amostras. 0 símbolo * indica $p<0,001$, \# $p<0,01$, e $p<0,05$ entre o grupo RV-G e o grupo C-G. 0 símbolo $\Phi$ indica $p<0,001$ de células controle (não expostas ao DOX), pelos testes ANOVA de uma via, e post hoc Tukey.

pode se dever a uma regulação do sistema de defesa antioxidante enzimático e não enzimático, que, por sua vez, neutraliza o ciclo fútil da produção de ERO durante a metabolização mitocondrial de DOX. Alinhado a isso, dados recentes publicados por nosso grupo demonstraram que uma regulação do sistema de defesa antioxidante nos cardiomiócitos neonatais é induzida pelo exercício durante a gestação, e protege células neonatais contra a toxicidade induzida por DOX. ${ }^{9}$

A DOX forma adutos com o DNA, que pode ativar respostas aos danos ao DNA e induzir a morte celular independentemente da topoisomerase II. ${ }^{38}$ A DOX também age como um veneno da topoisomerase II, gerando quebras de dupla hélice no DNA e morte celular. ${ }^{39} \mathrm{~A}$ ação celular da DOX também envolve danos à cromatina, mediada pela expulsão de histonas em sítios específicos do genoma. ${ }^{3}$ Por outro lado, a DOX pode mediar a morte celular pela geração de stress oxidativo que pode resultar no dano ao DNA. ${ }^{2,40}$ Recentemente, foi proposto por Qiao et al., ${ }^{41}$ que a cardiotoxicidade induzida por DOX exige a combinação de ambas atividades celulares, particularmente a combinação de danos ao DNA e à cromatina induzidos pela cardiotoxicidade. Além disso, o dano à cromatina causado pela expulsão de histonas no genoma é apontada como ação essencial para a eficácia quimioterápica do fármaco, que deve ser desatrelada das quebras de dupla hélice e danos ao DNA nas células, que, em conjunto, são responsáveis pela cardiotoxicidade da DOX. ${ }^{3,41}$

Nesta pesquisa, células neonatais tratadas com DOX apresentaram um aumento de danos oxidativos ao DNA, avaliadas pelas atividades das enzimas FPG e EndollI, que estavam correlacionadas ao aumento da produção do stress oxidativo gerado pela DOX. Entretanto, células neonatais de mães que receberam resveratrol apresentaram uma redução das quebras de DNA, através da avaliação por Endolll ou FPG. Essa cardioproteção oferecida pelo resveratrol pode ser devida a seu perfil antioxidante, conforme mencionado anteriormente, já que consegue atravessar a barreira placentária. Entretanto, mecanismos adicionais podem estar envolvidos, tais como a regulação das enzimas reparadoras dos danos ao DNA.

Alinhado a isso, a Sirt6 é uma desacetilase de histonas (HDAC) com um papel central no reparo do DNA. ${ }^{42,43}$ Nossos resultados demonstraram que os cardiomiócitos 
neonatais, de ratos que receberam resveratrol, expostos à DOX, demonstraram um aumento na expressão da Sirt6, que pode ser justificado pela ação protetora do resveratrol no dano ao DNA induzido em nosso modelo. A Sirt6 é uma proteína scaffold que, após os danos ao DNA, é atraída a quebras de hélices, ativando agentes de reparo de danos ao DNA para um reparo eficiente. ${ }^{42,44}$ Além disso, a Sirt6 liga-se à PARP-1, uma enzima com função importante na regulação de processos celulares e subcelulares, incluindo reparo ao DNA, ciclo celular, expressão genética, e morte celular. ${ }^{45,46}$

De forma semelhante a outras HDACs, classe III, a atividade da Sirt6 é dependente da NAD ${ }^{+}$- uma coenzima com papel central nas reações metabólicas de oxiredução. ${ }^{47}$ Essa relação entre $\mathrm{NAD}^{+}$e Sirt6 no coração é confirmada durante uma situação de hipertrofia cardíaca, em que os níveis de $\mathrm{NAD}^{+}$diminuem e a Sirt6 é inativada. ${ }^{44}$ A cardioproteção oferecida pelo resveratrol nesse modelo pode se dever ao aumento dos níveis de $\mathrm{NAD}^{+}$, já que o resveratrol inibe a atividade de síntese de ATP na mitocôndria ligando-se à subunidade $\mathrm{G}$ e prejudicando a fosforilação de ATP na mitocôndria. ${ }^{48}$ Consequentemente, o resveratrol aumenta a proporção AMP/ATP, ativando a AMPK (proteína quinase ativada por AMP), ${ }^{49}$ aumentando a $\mathrm{NAD}^{+}$, que agem como sensor metabólico da ativação da Sirt6. Demonstrou-se também que o resveratrol protege fibroblastos embrionários contra a cardiotoxicidade induzida por DOX pela ativação da AMPK, por meio de uma diminuição da produção de ERO. ${ }^{50}$

Entretanto, a expressão da Sirt6 não foi alterada em cardiomiócitos neonatais de ratas do grupo controle, que exibiram um aumento nos danos oxidativos ao DNA induzidos pela DOX e produção de stress oxidativo, sugerindo que a falta de cardioproteção é dependente da expressão da Sirt6. Notadamente, a expressão da Sirt6 não foi alterada em cardiomiócitos não expostos a DOX, independentemente da suplementação materna com resveratrol. Como a Sirt6 é vista como uma proteína de defesa, que ativa vias de defesa para sobrevivência em situações estressantes, tais como o dano hipóxico ou hipertrofia cardíaca, ${ }^{44,51}$ é possível que a toxicidade induzida por DOX sobre cardiomiócitos foi o gatilho para sua atividade.

Portanto, nesse estudo, o efeito benéfico do resveratrol na toxicidade induzida por DOX no coração de filhotes de ratos foi demonstrado, pela primeira vez, por meio da suplementação das mães durante a gestação. Em relação às propriedades antioxidantes do resveratrol observadas nesta pesquisa, a maioria de seus efeitos cardioprotetores foi mediada pela superexpressão da Sirt6 e aumento da resposta aos danos ao DNA, preservando a integridade do DNA. Esses efeitos, juntamente com a modulação de enzimas antioxidantes e redução de stress oxidativo celular, contribuem para a sobrevivência de cardiomiócitos sob toxicidade induzida por DOX. Entretanto, são necessários estudos adicionais para definir o papel dos alvos de desacetilação da Sirt6, e epigenética no fenótipo cardioprotetor gerado pelo resveratrol na ninhada nesse modelo de cardiotoxicidade induzida por DOX.

\section{Limitações}

As principais limitações deste estudo foram a impossibilidade de se utilizar métodos para quantificar a dosagem de resveratrol no sangue dos filhotes, o que poderia evidenciar ou excluir a possibilidade de efeito direto do resveratrol. Além disso, a avaliação dos alvos de desacetilação da Sirt6 poderia esclarecer o papel da modulação epigenética neste modelo.

\section{Conclusão}

Nossa pesquisa demonstra, pela primeira vez, que a administração de baixas doses de resveratrol durante a gestação pode proteger cardiomiócitos de filhotes contra a toxicidade induzida por DOX. Essa proteção ocorreu pela regulação do stress oxidativo pelo sistema de defesa antioxidante e o aumento da resposta ao reparo dos danos ao DNA, mediada pela superexpressão da Sirt6. Tomados em conjunto, esses resultados denotam um envolvimento importante do ambiente materno nas respostas a agentes estressantes da prole durante toda a vida.

\section{Agradecimentos}

Agradecemos à FAPERGS (Fundação de Amparo à Pesquisa do Estado do Rio Grande do Sul) e à CAPES (Coordenação de Aperfeiçoamento de Pessoal de Nível Superior) pelas bolsas concedidas a VBB e LVMN.

\section{Contribuição dos autores}

Concepção e desenho da pesquisa: Brito VB, Moura DJ, Saffi J; Obtenção de dados: Brito VB, Nascimento LVM; Análise e interpretação dos dados e Revisão crítica do manuscrito quanto ao conteúdo intelectual importante: Brito VB, Nascimento LVM, Moura DJ, Saffi J; Análise estatística e Redação do manuscrito: Brito VB; Obtenção de financiamento: Saffi J.

\section{Potencial conflito de interesse}

Não há conflito de interesse no presente artigo.

\section{Fontes de financiamento}

O presente estudo foi parcialmente financiado pelas agências FAPERGS e CAPES.

\section{Vinculação acadêmica}

Este artigo é parte de tese de Doutorado de Verônica Bidinotto Brito pela Universidade Federal de Ciências da Saúde de Porto Alegre. 


\section{Referências}

1. Deng Y, Li F, He P, Yang Y, Yang J, Zhang Y, et al. Triptolide sensitizes breast cancer cells to Doxorubicin through the DNA damage response inhibition. Mol Carcinog. 2018 Jun 1;57(6):807-14.

2. Minotti G, Menna P, Salvatorelli E, Cairo G, Gianni L. Anthracyclines: molecular advances and pharmacologic developments in antitumor activity and cardiotoxicity. Pharmacol Rev. 2004 Jun;56(2):185-229.

3. Pang B, Qiao X, Janssen L, Velds A, Groothuis T, Kerkhoven R, et al. Drug-induced histone eviction from open chromatin contributes to the chemotherapeutic effects of doxorubicin. Nat Commun. 2013 Jan;4:1908. doi:https//doi.org/10.1038/ncomms2921

4. McGowan J V, Chung R, Maulik A, Piotrowska I, Walker JM, Yellon DM. Anthracycline Chemotherapy and Cardiotoxicity. Cardiovasc Drugs Ther. 2017 Feb 9;31(1):63-75.

5. Štěrba M, Popelová O, Vávrová A, Jirkovský E, Kovaříková P, Geršl V, et al. Oxidative Stress, Redox Signaling, and Metal Chelation in Anthracycline Cardiotoxicity and Pharmacological Cardioprotection. Antioxid Redox Signal. 2013 Mar 10;18(8):899-929.

6. Schlitt A, Jordan K, Vordermark D, Schwamborn J, Langer T, Thomssen C. Cardiotoxicity and oncological treatments. Dtsch Ärzteblatt Int. 2014 Mar 7;111(10):161-8.

7. Andreadou I, Mikros E, loannidis K, Sigala F, Naka K, Kostidis S, et al. Oleuropein prevents doxorubicin-induced cardiomyopathy interfering with signaling molecules and cardiomyocyte metabolism. J Mol Cell Cardiol. 2014;69:4-16.

8. Marques-Aleixo I, Santos-Alves E, Mariani D, Rizo-Roca D, Padrão AI, RochaRodrigues $\mathrm{S}$, et al. Physical exercise prior and during treatment reduces subchronic doxorubicin-induced mitochondrial toxicity and oxidative stress. Mitochondrion. 2015;20:22-33.

9. Brito VB, Nascimento LVM, Nunes RB, Moura DJ, Lago PD, Saffi J. Exercise during pregnancy decreases doxorubicin-induced cardiotoxic effects on neonatal hearts. Toxicology. 2016 Aug 10;368-369:46-57.

10. Catalgol B, Batirel S, Taga Y, Ozer NK. Resveratrol: French paradox revisited. Front Pharmacol. 2012 Jan;3:141

11. Bonechi C, Lamponi S, Donati A, Tamasi G, Consumi M, Leone G, et al. Effect of resveratrol on platelet aggregation by fibrinogen protection. Biophys Chem. 2017 Mar;222:41-8.

12. Bariani MV, Correa F, Leishman E, Domínguez Rubio AP, Arias A, Stern A, et al. Resveratrol protects from lipopolysaccharide-induced inflammation in the uterus and prevents experimental preterm birth. MHR Basic Sci Reprod Med. 2017 Aug 1;23(8):571-81.

13. Zhang H-X, Duan G-L, Wang C-N, Zhang Y-Q, Zhu X-Y, Liu Y-J. Protective effect of resveratrol against endotoxemia-induced lung injury involves the reduction of oxidative/nitrative stress. Pulm Pharmacol Ther. 2014;27(2):150-5.

14. Aggarwal BB, Prasad S, Reuter S, Kannappan R, Yadev VR, Park B, et al. Identification of novel anti-inflammatory agents from Ayurvedic medicine for prevention of chronic diseases: "reverse pharmacology" and "bedside to bench" approach. Curr Drug Targets. 2011 Oct;12(11):1595-653.

15. Jin $\mathrm{H}, \mathrm{Wu} \mathrm{G}, \mathrm{Wu} \mathrm{G}$, Bao Y. Combining the mammalian target of rapamycin inhibitor, rapamycin, with resveratrol has a synergistic effect in multiple myeloma. Oncol Lett. 2018 Mar 5;15(5):6257-64.

16. Mathias PCF, Elmhiri G, De Oliveira JC, Delayre-Orthez C, Barella LF, Tofolo $\mathrm{LP}$, et al. Maternal diet, bioactive molecules, and exercising as reprogramming tools of metabolic programming. Eur J Nutr. 2014;53(3):711-22.

17. de Velasco PC, Chicaybam G, Ramos-Filho DM, dos Santos RMAR, MairinkC, Sardinha FLC, etal. Maternal intake of trans-unsaturated or interesterified fatty acids during pregnancy and lactation modifies mitochondrial bioenergetics in the liver of adult offspring in mice. Br J Nutr. 2017 Aug 11;118(1):1-12.

18. Singh CK, Kumar A, Hitchcock DB, Fan D, Goodwin R, LaVoie HA, et al. Resveratrol prevents embryonic oxidative stress and apoptosis associated with diabetic embryopathy and improves glucose and lipid profile of diabetic dam. Mol Nutr Food Res. 2011 Aug;55(8):1186-96

19. Care AS, Sung MM, Panahi S, Gragasin FS, DyckJRB, Davidge ST, et al. Perinatal Resveratrol Supplementation to Spontaneously Hypertensive Rat Dams Mitigates the Development of Hypertension in Adult OffspringNovelty and Significance. Hypertension. 2016 May;67(5):1038-44.

20. Movahed A, Yu L, Thandapilly SJ, Louis XL, Netticadan T. Resveratrol protects adult cardiomyocytes against oxidative stress mediated cell injury. Arch Biochem Biophys. 2012 Nov 15;527(2):74-80.

21. Venturini CD, Merlo S, Souto AA, Fernandes MDC, Gomez R, Rhoden CR. Resveratrol and red wine function as antioxidants in the nervous system without cellular proliferative effects during experimental diabetes. Oxid Med Cell Longev. 2010;3(6):434-41.

22. Robichová S, Slameňová D. Effects of vitamins $C$ and $E$ on cytotoxicity induced by $\mathrm{N}$-nitroso compounds, $\mathrm{N}$-nitrosomorpholine and $\mathrm{N}$-methyl- $\mathrm{N}^{\prime}$-nitro$\mathrm{N}$-nitrosoguanidine in Caco-2 and V79 cell lines. Cancer Lett. 2002 Aug $8 ; 182(1): 11-8$

23. Singh NP, McCoy MT, Tice RR, Schneider EL. A simple technique for quantitation of low levels of DNA damage in individual cells. Exp Cell Res. 1988 Mar;175(1):184-91.

24. Hartmann A, Speit G. The contribution of cytotoxicity to DNA-effects in the single cell gel test (comet assay). Toxicol Lett. 1997 Feb 7;90(2-3):183-8.

25. Nadin SB, Vargas-Roig LM, Ciocca DR. A silver staining method for single-cell gel assay. J Histochem Cytochem. 2001 Sep;49(9):1183-6.

26. Hartmann A, Agurell E, Beevers C, Brendler-Schwaab S, Burlinson B, Clay P, et al. Recommendations for conducting the in vivo alkaline Comet assay. 4th International Comet Assay Workshop. Mutagenesis. 2003 Jan;18(1):45-51.

27. LeBel CP, Ischiropoulos H, Bondy SC. Evaluation of the probe $2^{\prime}, 7^{\prime}$-dichlorofluorescin as an indicator of reactive oxygen species formation and oxidative stress. Chem Res Toxicol. 1992 Mar;5(2):227-31.

28. Misra HP, Fridovich I. The role of superoxide anion in the autoxidation of epinephrine and a simple assay for superoxide dismutase therRole of superoxide anion in the epinephrine and a simple assay for superoxide dismutase. J Biol Chem. 1972;247(10):3170-5.

29. Aebi H. Catalase in vitro. Methods Enzymol. 1984 Jan;105:121-6.doi:10.1016/ s0076-6879(84)0516-3

30. Ellman GL. Tissue sulfhydryl groups. Arch Biochem Biophys. 1959 May;82(1):70-7.

31. Towbin H, Staehelin T, Gordon J. Electrophoretic transfer of proteins from polyacrylamide gels to nitrocellulose sheets: procedure and some applications. Proc Natl Acad Sci. 1979 Sep 1;76(9):4350-4.

32. Lowry OH, Rosebrough NJ, Farr AL, Randall RJ. Protein measurement with the Folin phenol reagent. J Biol Chem. 1951 Nov;193(1):265-75.

33. Dušinská M, Collins A. Detection of oxidised purines and UV-induced photoproducts in DNA of single cells, by inclusion of Lesion-specific enzymes in the comet assay. ATLAAltern to Lab Anim. 1996;24(3):405-11.

34. Collins AR, Duthie SJ, Dobson VL. Direct enzymic detection of endogenous oxidative base damage in human lymphocyte DNA. Carcinogenesis. 1993 Sep;14(9):1733-5

35. Zhu H-L. Resveratrol and Its Analogues: Promising Antitumor Agents. Anticancer Agents Med Chem. 2011 Jun 1;11(5):479-90.

36. Kotora P, Šeršěn F, Filo J, Loos D, Gregáň J, Gregáň F. The scavenging of DPPH, galvinoxyl and ABTS radicals by imine analogs of resveratrol. Molecules. 2016 Jan 21;21(1):127.

37. Andriantsitohaina R, Auger C, Chataigneau T, Étienne-Selloum N, LiH, Martínez MC, et al. Molecular mechanisms of the cardiovascular protective effects of polyphenols. Br J Nutr. 2012 Nov;108(09):1532-49. 
38. Cutts SM, Rephaeli A, Nudelman A, Ugarenko M, Phillips DR. Potential Therapeutic Advantages of Doxorubicin when Activated by Formaldehyde to Function as a DNA Adduct-Forming Agent. Curr Top Med Chem. 2015;15(14):1409-22.

39. Pommier $\mathrm{Y}$, Leo E, Zhang H, Marchand C. DNA topoisomerases and their poisoning by anticancer and antibacterial drugs. Chem Biol. 2010 May 28;17(5):421-33.

40. Stěrba M, Popelová O, Vávrová A, Jirkovský E, Kovaříková $\mathrm{P}$, Geršl V, et al. Oxidative stress, redox signaling, and metal chelation in anthracycline cardiotoxicity and pharmacological cardioprotection. Antioxid Redox Signal. 2013 Mar 10;18(8):899-929.

41. Qiao X, van der Zanden SY, Wander DPA, Borràs DM, Song J-Y, Li X, et al. Uncoupling DNA damage from chromatin damage to detoxify doxorubicin. Proc Natl Acad Sci U S A. 2020 Jun 30;117(26):15182-92.

42. Toiber D, Erdel F, Bouazoune K, Silberman DM, Zhong L, Mulligan $P$, et al. SIRT6 Recruits SNF2H to DNA Break Sites, Preventing Genomic Instability through Chromatin Remodeling. Mol Cell. 2013 Aug 22;51(4):454-68.

43. Kugel S, Mostoslavsky R. Chromatin and beyond: the multitasking roles for SIRT6. Trends Biochem Sci. 2014 Feb;39(2):72-81.

44. Cai Y, Yu S-S, Chen S-R, Pi R-B, Gao S, Li H, et al. Nmnat2 protects cardiomyocytes from hypertrophy via activation of SIRT6. FEBS Lett. 2012;586(6):866-74.
45. Van Meter M, Simon M, Tombline G, May A, Morello TD, Hubbard BP, et al. JNK Phosphorylates SIRT6 to Stimulate DNA Double-Strand Break Repair in Response to Oxidative Stress by Recruiting PARP1 to DNA Breaks. Cell Rep. 2016 Sep 6;16(10):2641-50.

46. Chang AR, Ferrer CM, Mostoslavsky R. SIRT6, a Mammalian Deacylase with Multitasking Abilities. Physiol Rev. 2020 Jan 1;100(1):145-69.

47. Radak Z, Koltai E, Taylor AW, Higuchi M, Kumagai S, Ohno H, et al. Redoxregulating sirtuins in aging, caloric restriction, and exercise. Free Radic Biol Med. 2013 May;58:87-97. doi:10.1016/j.freeradbiomed.2013.01.004

48. Ahmad Z, Hassan SS, Azim S. A Therapeutic Connection between Dietary Phytochemicals and ATP Synthase. Curr Med Chem. 2017 Nov 20;24(35):3894-906.

49. Koltai E, Szabo Z, Atalay M, Boldogh I, Naito H, Goto S, et al. Exercise alters SIRT1, SIRT6, NAD and NAMPT levels in skeletal muscle of aged rats. Mech Ageing Dev. 2010;131(1):21-8.

50. Balteau M, Van Steenbergen A, Timmermans AD, Dessy C, BehetsWydemans $\mathrm{G}$, Tajeddine N, et al. AMPK activation by glucagon-like peptide-1 prevents NADPH oxidase activation induced by hyperglycemia in adult cardiomyocytes. Am J Physiol Heart Circ Physiol. 2014 Oct 15;307(8):H1120-33.

51. Maksin-Matveev A, Kanfi Y, Hochhauser E, Isak A, Cohen HY, Shainberg A. Sirtuin 6 protects the heart from hypoxic damage. Exp Cell Res. 2015 Jan 1;330(1):81-90. 